\title{
Relationship between rock uniaxial compressive strength and digital core drilling parameters and its forecast method
}

\author{
Hongke Gao ${ }^{1,2,3} \cdot$ Qi Wang ${ }^{1,3} \cdot$ Bei Jiang ${ }^{2,3} \cdot$ Peng Zhang ${ }^{1,4} \cdot$ Zhenhua Jiang $^{1,4}$ • \\ Yue Wang ${ }^{1,4}$
}

Received: 28 February 2020/Revised: 13 July 2020/ Accepted: 20 November 2020/Published online: 3 January 2021

(C) The Author(s) 2021

\begin{abstract}
The rock uniaxial compressive strength (UCS) is the basic parameter for support designs in underground engineering. In particular, the rock UCS should be obtained rapidly for underground engineering with complex geological conditions, such as soft rock, fracture areas, and high stress, to adjust the excavation and support plan and ensure construction safety. To solve the problem of obtaining real-time rock UCS at engineering sites, a rock UCS forecast idea is proposed using digital core drilling. The digital core drilling tests and uniaxial compression tests are performed based on the developed rock mass digital drilling system. The results indicate that the drilling parameters are highly responsive to the rock UCS. Based on the cutting and fracture characteristics of the rock digital core drilling, the mechanical analysis of rock cutting provides the digital core drilling strength, and a quantitative relationship model (CDP-UCS model) for the digital core drilling parameters and rock UCS is established. Thus, the digital core drilling-based rock UCS forecast method is proposed to provide a theoretical basis for continuous and quick testing of the surrounding rock UCS.
\end{abstract}

Keywords Digital core drilling · Mechanical analysis · Rock UCS · Quantitative relationship model · Forecast method

\section{List of symbols \\ UCS Uniaxial compressive strength (MPa) \\ DCS Digital core drilling strength (MPa) \\ $V \quad$ Drilling rate $(\mathrm{mm} / \mathrm{min})$ \\ $N \quad$ Rotating speed $(\mathrm{r} / \mathrm{min})$ \\ $F \quad$ Drilling thrust $(\mathrm{kN})$ \\ $M \quad$ Drilling torque $(\mathrm{N} \mathrm{m})$ \\ $h \quad$ Drilling depth (mm)}

Qi Wang

chinawangqi@163.com

1 Geotechnical and Structural Engineering Research Center, Shandong University, Jinan 250061, China

2 State Key Laboratory for GeoMechanics and Deep Underground Engineering, China University of Mining and Technology, Xuzhou 221116, China

3 State Key Laboratory for GeoMechanics and Deep Underground Engineering, China University of Mining and Technology, Beijing 100083, China

4 Shandong Tianqin Mining Machinery Equipment Co., Ltd., Yuncheng 274700, China $t \quad$ Drilling time (min)

$\lambda$ Response evaluation index of $M$ to the rock UCS ( $\mathrm{N} \mathrm{m} / \mathrm{MPa}$ )

$H \quad$ Instantaneous cutting depth (mm)

$M_{c} \quad$ Cutting torque $(\mathrm{N} \mathrm{m})$

$F_{c} \quad$ Resistance from the front rock on the cutting edge (N/mm)

$M_{f} \quad$ Friction torque $(\mathrm{N} \mathrm{m})$

$F_{f} \quad$ Force from the rock at the bottom of the hole on the cutting edge $(\mathrm{N} / \mathrm{mm})$

$R \quad$ Radius of the special digital core drilling bit ( $\mathrm{mm}$ )

$l \quad$ Length of each row of the cutting edge $(\mathrm{mm})$

$\alpha \quad$ Angle between the force $F_{c}$ and the normal direction of the cutting edge surface $\left(^{\circ}\right.$ )

$\theta \quad$ Inclination angle of the cutting edge $\left(^{\circ}\right)$

$\beta \quad$ Angle between the force $F_{f}$ and the vertical direction $\left(^{\circ}\right)$ 


\section{Introduction}

The rock uniaxial compressive strength (UCS) is an indispensable parameter in rock mass stability analysis, underground chamber excavation, and support design for transportation, mines, and hydraulic projects. Accurate acquisition of the UCS is a precondition for engineering construction. In particular, the rock UCS should be obtained rapidly for underground engineering with complex geological conditions, such as soft rock, fracture areas, and high stress (Cao et al. 2016; Wang et al. 2017b, 2018, 2019, 2020a, b; Yang et al. 2017) to adjust the excavation and support plan and ensure construction safety. The conventional rock uniaxial compression test is a common method to measure the rock UCS (Chen et al. 2017; Liu et al. 2018; Meng et al. 2016; Xu and Dai 2017). However, on-site core drilling and laboratory testing is required, which is a cumbersome process with long measurement periods. Thus, the surrounding rock UCS at a construction site cannot be obtained in real-time, and effectively obtaining rock core specimens for UCS measurements from the fractured surrounding rock is difficult. Therefore, an in situ test method to measure the surrounding rock UCS in engineering sites in real-time is needed.

The point load method (Heidari et al. 2012; Kaya and Karaman 2016; Ozturk and Altinpinar 2017) and Schmidt hammer testing (Goktan and Gunes 2005; Wang et al. 2017a) are commonly used in situ methods to measure rock strength. However, the surrounding rock needs to be core drilled to obtain the rock strength for these methods. Some researchers have investigated in situ rock UCS forecasting based on regression analysis or artificial neural networks (Dehghan et al. 2010; Moradian and Behnia 2009; Sharma et al. 2017; Tiryaki 2008; Torabi-Kaveh et al. 2015; Yesiloglu-Gultekin et al. 2013). The majority of previous in situ rock strength testing methods only support measurements of the rock UCS at a limited number of points. The UCS from a chamber surface to the surrounding rock at a considerable depth does not enable continuous measurements. Therefore, developing a continuous and quick test method for the rock strength parameters in situ has become the key focus of geotechnical test technology research.

This analysis reveals that drilling is required in the majority of surrounding rock strength parameter testing methods. Quick in situ measurements of rock strength will be achieved if the rock UCS is obtained during drilling. Digital drilling test technology (Ersoy 2003; Gui et al. 2002; Munoz et al. 2016; Sugawara et al. 2003; Yue et al. 2004) provides an effective means to support real-time monitoring of drilling parameters, including the rate, thrust, rotating speed, and torque. Studies by several researchers have indicated that the digital drilling parameters and rock UCS are correlated (Aalizad and Rashidinejad 2012; Ataei et al. 2015; Fattahi and Bazdar 2017; Kumar et al. 2011; Li and Itakura 2012; Yaşar et al. 2011).

The drilling parameters and rock core at the corresponding positions can be obtained during digital core drilling of the surrounding rock. The rock UCS from laboratory testing is compared with the forecasted value from the drilling parameters. A quantitative relationship model for the drilling parameters and rock UCS is continuously modified to form the rock UCS digital core drilling realtime acquisition method. Therefore, this surrounding rock digital core drilling test provides a new approach for the continuous and real-time acquisition of rock UCS on site. The key to this approach is establishing a quantitative relationship between the digital core drilling parameters and the rock UCS.

To achieve real-time acquisition of the rock UCS, digital core drilling tests and uniaxial compression tests are conducted on cement mortar specimens of varying strengths and sandstone specimens to determine the drilling parameters and UCS. These tests are based on the rock mass digital drilling test system and a specially developed digital core bit. The mechanical analysis of rock cutting is performed to obtain the digital core drilling strength (DCS). A quantitative relationship model (CDP-UCS model) between the digital core drilling parameters and rock UCS is generated for the proposed digital core drilling-based rock UCS forecast method.

\section{Digital core drilling test}

\subsection{Test equipment}

The rock digital core drilling test is based on a rock mass digital drilling system that was developed by the authors, as shown in Fig. 1. This test equipmement includes the drilling system, the loading system, the pressure chamber, and the monitoring and control system with a maximum drilling thrust and rotating speed of $50 \mathrm{kN}$ and $400 \mathrm{r} / \mathrm{min}$, respectively. The overall dimensions of the main device are $1750 \mathrm{~mm} \times 2350 \mathrm{~mm} \times 4335 \mathrm{~mm}$. During drilling, the system supports real-time monitoring and control of the drilling parameters, including the drilling rate $V(\mathrm{~mm} / \mathrm{min})$, rotating speed $N(\mathrm{r} / \mathrm{min})$, drilling thrust $F(\mathrm{kN})$, and drilling torque $M(\mathrm{~N} \mathrm{~m})$. Thus, four control modes of constant $V-N$, constant $V-M$, constant $F-N$, and constant $F-M$ are formed, and rock digital drilling tests under multiple control modes are realized.

A specially designed PDC (Polycrystalline Diamond Compact) bit for digital core drilling is used, which 


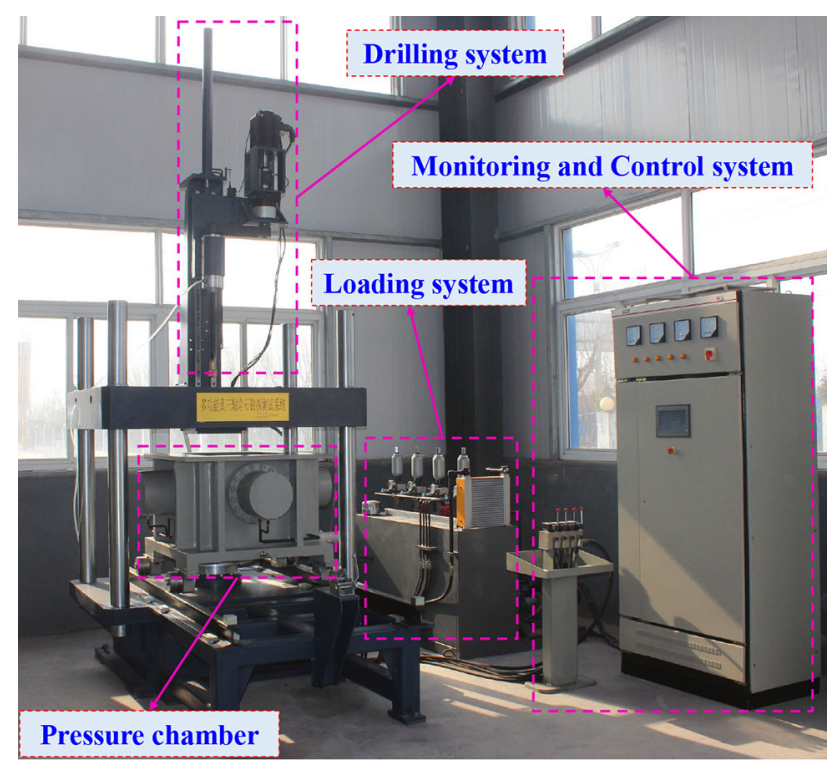

Fig. 1 Rock mass digital drilling system

consists of the rectangular PDC and matrix, as shown in Fig. 2. The rock cutting mechanical analysis of the drill bit conforms to the theoretical hypothesis, and the rectangular compact design ensures that the shape and stress characteristics remain unchanged to reduce the impact of compact wear on the test data, even if the compact wears during drilling.

\subsection{Test plan design}

The specimens in the digital drilling test include cement mortar specimens with various strengths and sandstone specimens. The sandstone specimens are made from relatively intact natural rock, and the cement mortar specimens are prepared based on seven mix ratios to simulate intact rock of different strengths, as listed in Table 1. Three groups are prepared for each type of test specimen, giving a

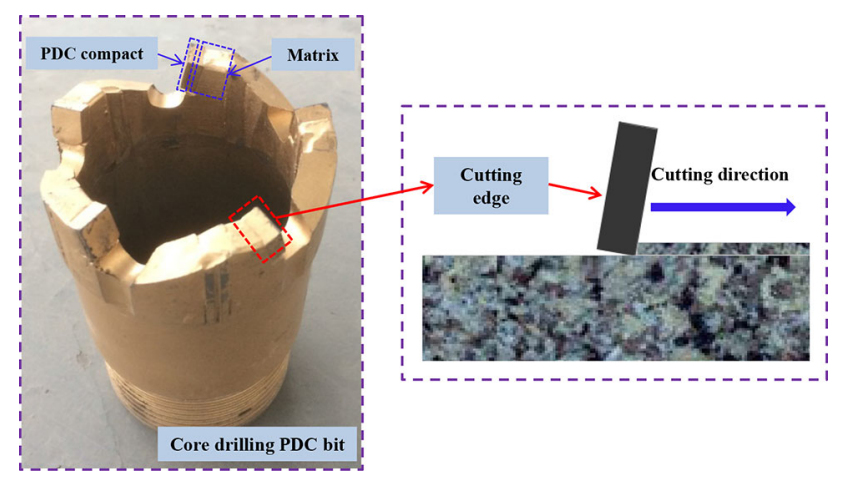

Fig. 2 Special PDC bit for digital core drilling
Table 1 Material consumption of making cement mortar specimens with various strength grades per $\mathrm{m}^{3}$

\begin{tabular}{lllll}
\hline $\begin{array}{l}\text { Strength } \\
\text { grade }\end{array}$ & $\begin{array}{l}\text { Cement } \\
(\mathrm{kg})\end{array}$ & $\begin{array}{l}\text { Cement strength } \\
\text { grade }\end{array}$ & $\begin{array}{l}\text { River sand } \\
(\mathrm{kg})\end{array}$ & $\begin{array}{l}\text { Water } \\
(\mathrm{kg})\end{array}$ \\
\hline S1 & 210 & 32.5 & 1450 & 300 \\
S2 & 260 & & & \\
S3 & 200 & 42.5 & & \\
S4 & 360 & & & \\
S5 & 410 & & & \\
S6 & 460 & & & \\
S7 & 700 & & & \\
\hline
\end{tabular}

total of 24 groups. The specimen dimensions are as follows: length $\times$ width $\times$ height $=150 \mathrm{~mm} \times 150 \mathrm{~mm} \times$ $200 \mathrm{~mm}$.

The digital core drilling test controls the drilling rate $V$ and rotating speed $N$ while monitoring the thrust $F$ and torque $M$. The $V$ and $N$ are set to one of two levels: 60 or $85 \mathrm{~mm} / \mathrm{min}$ and 50 or $100 \mathrm{r} / \mathrm{min}$, respectively. The cement mortar specimens with seven strength grades are numbered as $\mathrm{S} 1-\mathrm{S} 7$, and the sandstone specimen is numbered as $\mathbf{S} 8$. The core drilling depth of the test specimen is $150 \mathrm{~mm}$. After the drilling tests, the rock core is collected, cut, and polished to prepare the conventional specimens for the UCS measurements, which is based on the "Standard Test Methods for Compressive Strength and Elastic Moduli of Intact Rock Core Specimens under Varying States of Stress and Temperatures" (ASTM Standard Designation: D7012-14). The dimensions of the prepared rock core specimens are diameter $\times$ height $=50 \mathrm{~mm} \times 100 \mathrm{~mm}$. The detailed test plan is given in Table 2 .

\section{Statistics and analysis of test results}

\subsection{Statistics of drilling parameter results}

The rock digital core drilling tests are performed based on the test plan in Table 2. The specimens before and after the tests are shown in Fig. 3. During the digital core drilling test, the $V, N, M$, and $F$ are monitored in real-time. Typical test data from specimen S53 are taken as an example, and the drilling parameter curves are shown in Figs. 4 and 5, where $V=h / t, h$ is the drilling depth and $t$ is the drilling time.

As shown in Fig. 4, the $V$ and $N$ for drilling specimen S53 stabilize at the predefined values of $85 \mathrm{~mm} / \mathrm{min}$ and $100 \mathrm{r} / \mathrm{min}$, respectively, which give the desired control results. As shown in Fig. 5 for the drilling specimen S53, the trends of $F$ and $M$ with $h$ are similar. As the drilling depth increases, $F$ and $M$ rapidly increase at the initial stage and then stabilize and fluctuate over a small range. 
Table 2 Digital core drilling test plan

\begin{tabular}{|c|c|c|c|c|c|c|c|}
\hline \multicolumn{2}{|c|}{$\begin{array}{l}\text { No. of } \\
\text { specimens }\end{array}$} & \multirow{2}{*}{$\begin{array}{l}V(\mathrm{~mm} / \\
\mathrm{min})\end{array}$} & \multirow{2}{*}{$\begin{array}{c}\begin{array}{c}N(\mathrm{r} / \\
\min )\end{array} \\
50\end{array}$} & \multicolumn{2}{|c|}{$\begin{array}{l}\text { No. of } \\
\text { specimens }\end{array}$} & \multirow{2}{*}{$\begin{array}{l}V(\mathrm{~mm} / \\
\mathrm{min}) \\
60\end{array}$} & \multirow{2}{*}{$\begin{array}{c}N(\mathrm{r} / \\
\min )\end{array}$} \\
\hline S1 & S11 & & & S2 & $\mathrm{S} 21$ & & \\
\hline & $\mathrm{S} 12$ & 60 & 100 & & S22 & 60 & 100 \\
\hline & $\mathrm{S} 13$ & 85 & 100 & & $\mathrm{~S} 23$ & 85 & 100 \\
\hline \multirow[t]{3}{*}{$\mathrm{S} 3$} & $\mathrm{~S} 31$ & 60 & 50 & S4 & S41 & 60 & 50 \\
\hline & $\mathrm{S} 32$ & 60 & 100 & & $\mathrm{~S} 42$ & 60 & 100 \\
\hline & S33 & 85 & 100 & & S43 & 85 & 100 \\
\hline \multirow[t]{3}{*}{ S5 } & S51 & 60 & 50 & S6 & S61 & 60 & 50 \\
\hline & S52 & 60 & 100 & & S62 & 60 & 100 \\
\hline & S53 & 85 & 100 & & S63 & 85 & 100 \\
\hline \multirow[t]{3}{*}{ S7 } & S71 & 60 & 50 & S8 & S81 & 60 & 50 \\
\hline & S72 & 60 & 100 & & S82 & 60 & 100 \\
\hline & S73 & 85 & 100 & & S83 & 85 & 100 \\
\hline
\end{tabular}

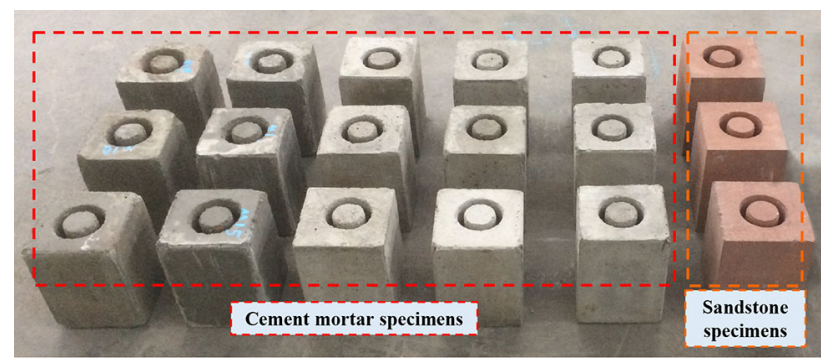

Fig. 3 Partial digital core drilling test specimens

The $F$ and $M$ test values are the averages of the stable segment minus their initial values. The $M$ measurement results from specimen S53 are taken as an example. The average value in the stable segment is $M_{\mathrm{a}}=33.99 \mathrm{~N} \mathrm{~m}$ with an initial value of $M_{\mathrm{i}}=17.0 \mathrm{~N} \mathrm{~m}$. Then, the test value of this specimen becomes $M=M_{\mathrm{a}}-M_{\mathrm{i}}=16.99 \mathrm{~N} \mathrm{~m}$ The monitoring results of $V, N, F$, and $M$ for all specimens are counted, and the standard rock UCS of the test specimen is measured. The detailed results are given in Table 3 .

\subsection{Analysis of responses for $M$ and $F$ to rock UCS}

Based on the test data in Table 3 , a $V$ of $60 \mathrm{~mm} / \mathrm{min}$ and $N$ of $100 \mathrm{r} / \mathrm{min}$ are taken as an example, the response laws for $M$ and $F$ to the rock UCS are analyzed, as shown in Figs. 6 and 7.

The analysis of Figs. 6 and 7 shows that the variation laws for $M$ and the $F$ to the rock UCS are consistent. Both laws demonstrate an overall increasing trend for a larger rock UCS. Therefore, intuitively analyzing the response degrees of the drilling parameters to the rock UCS allows using the drilling torque $M$ as an example to generate $\lambda$,
Drilling time $\boldsymbol{t}(\mathbf{m i n})$

$\begin{array}{llllllllll}0 & 0.2 & 0.4 & 0.6 & 0.8 & 1 & 1.2 & 1.4 & 1.6 & 1.8\end{array}$

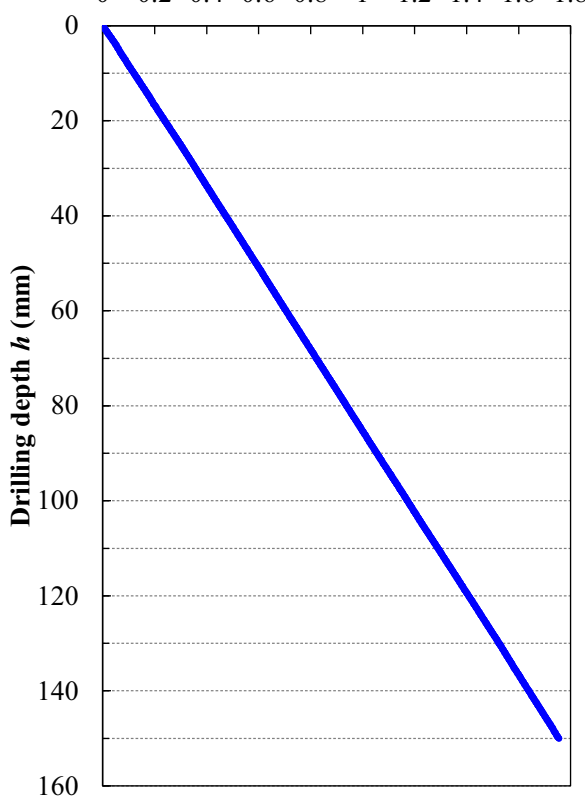

(a) Drilling depth $h$ versus drilling time $t$

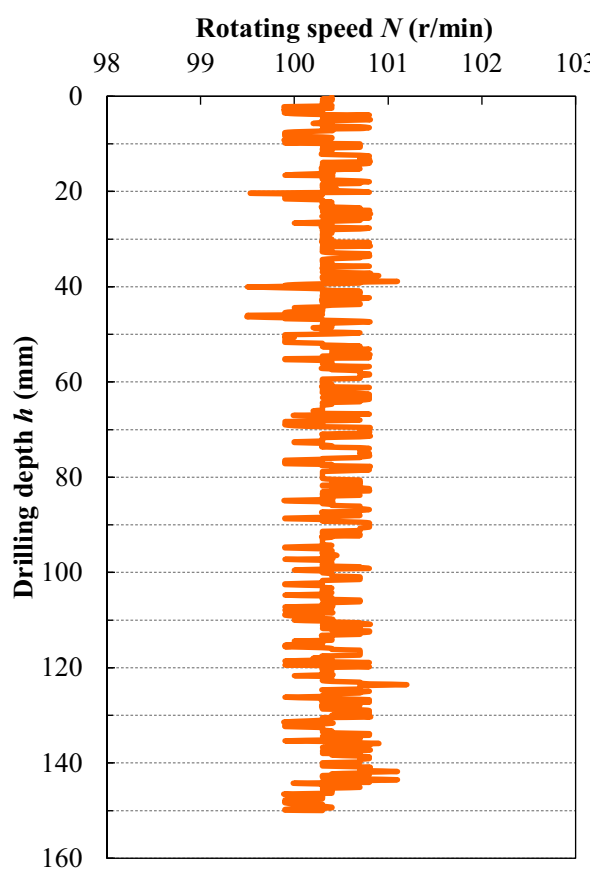

(b) Rotating speed $N$ versus drilling depth $h$

Fig. 4 Analysis curves of controlled drilling parameters

which is the response evaluation index of $M$ to the rock UCS.

$\lambda=\frac{|\Delta M|}{|\Delta \mathrm{UCS}|}$ 


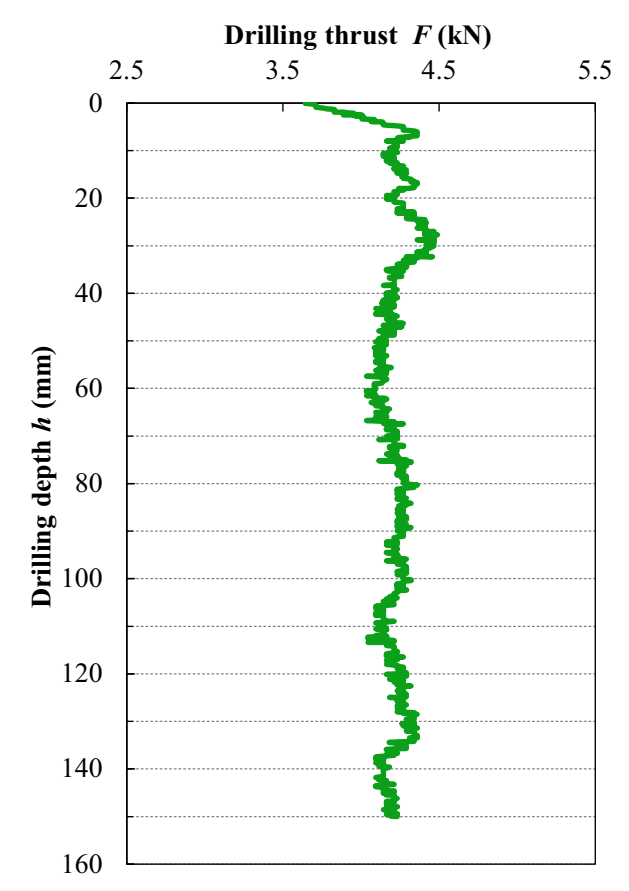

(a) Drilling thrust $F$ versus drilling depth $h$

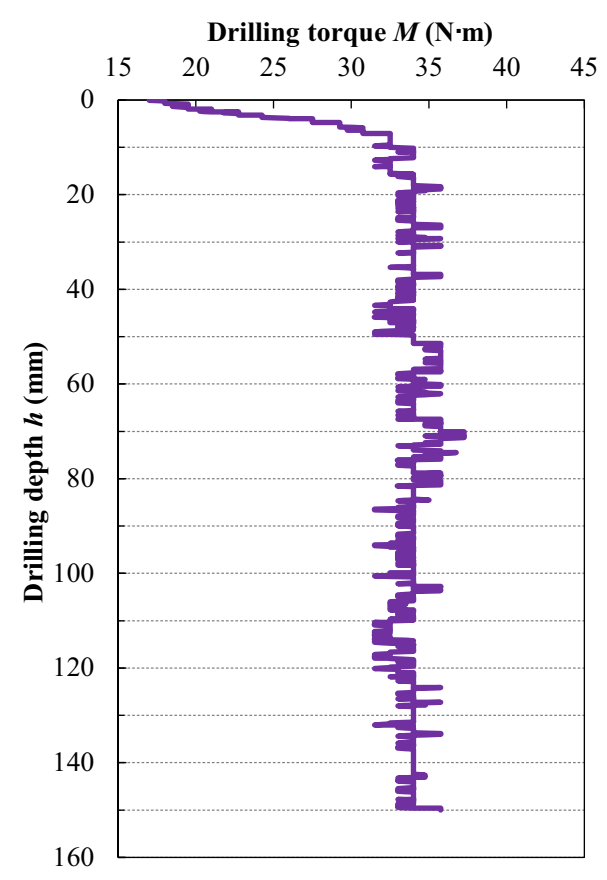

(b) Drilling torque $M$ versus drilling depth $h$

Fig. 5 Analysis curves of monitored drilling parameters

where, $\Delta M$ is the difference between monitored drilling torques $M$ in two plans, $\mathrm{N} \mathrm{m} ; \Delta \mathrm{UCS}$ is the difference between measured rock UCS in two plans, MPa.

Taking specimens S12 and S22 with small strength differences and specimens S72 and S82 with significant
Table 3 Statistics of digital core drilling test and uniaxial compression test results for test specimens

\begin{tabular}{llrlll}
\hline $\begin{array}{l}\text { No. of } \\
\text { specimens }\end{array}$ & $\begin{array}{l}V(\mathrm{~mm} / \\
\mathrm{min})\end{array}$ & $\begin{array}{r}N(\mathrm{r} / \\
\mathrm{min})\end{array}$ & $M(\mathrm{~N} \mathrm{~m})$ & $F(\mathrm{kN})$ & $\begin{array}{l}U C S \\
(\mathrm{MPa})\end{array}$ \\
\hline S11 & 60.05 & 50.94 & 3.71 & 0.31 & 1.56 \\
S12 & 60.06 & 100.34 & 2.34 & 0.19 & 1.85 \\
S13 & 85.19 & 100.43 & 3.49 & 0.26 & 2.03 \\
S21 & 60.08 & 50.89 & 5.74 & 0.32 & 2.83 \\
S22 & 60.21 & 100.36 & 4.15 & 0.30 & 3.41 \\
S23 & 84.67 & 100.35 & 5.38 & 0.43 & 2.83 \\
S31 & 59.48 & 50.96 & 6.24 & 0.34 & 7.10 \\
S32 & 59.60 & 100.50 & 4.27 & 0.27 & 7.11 \\
S33 & 86.07 & 100.43 & 3.57 & 0.24 & 7.30 \\
S41 & 60.12 & 50.89 & 17.12 & 0.87 & 11.82 \\
S42 & 59.89 & 100.39 & 10.62 & 0.76 & 11.38 \\
S43 & 85.80 & 100.40 & 12.08 & 0.55 & 11.83 \\
S51 & 59.93 & 50.95 & 20.08 & 0.89 & 18.37 \\
S52 & 60.22 & 100.37 & 12.96 & 0.77 & 18.87 \\
S53 & 85.89 & 100.41 & 16.99 & 0.71 & 19.95 \\
S61 & 59.89 & 50.94 & 25.20 & 1.11 & 19.82 \\
S62 & 60.19 & 100.35 & 15.83 & 0.85 & 20.66 \\
S63 & 85.74 & 100.39 & 20.98 & 0.91 & 21.98 \\
S71 & 59.53 & 51.03 & 43.25 & 1.94 & 35.22 \\
S72 & 59.51 & 100.57 & 22.75 & 1.19 & 35.87 \\
S73 & 85.60 & 100.44 & 33.50 & 1.34 & 36.05 \\
S81 & 60.35 & 50.79 & 66.85 & 2.29 & 48.35 \\
S82 & 61.29 & 100.33 & 40.25 & 1.85 & 49.80 \\
S83 & 83.87 & 100.29 & 56.50 & 2.11 & 55.68 \\
\hline & & & & &
\end{tabular}

strength differences as examples, the $\lambda$ between specimens $\mathrm{S} 12$ and $\mathrm{S} 22$ is $1.15 \mathrm{~N} \mathrm{~m} / \mathrm{MPa}$, while that between specimens S72 and S82 is $1.26 \mathrm{~N} \mathrm{~m} / \mathrm{MPa}$. The difference value in the responses of $M$ to the UCS is relatively small for plans with significant or small strength differences. Therefore, the monitored drilling parameters during rock drilling are highly responsive to the UCS.

\section{Quantitative relationships between drilling parameters and rock UCS}

\subsection{Mechanical analysis of rock cutting}

The aforementioned response laws of the core drilling parameters to the UCS indicate that rock UCS forecasting is feasible based on the digital core drilling parameters. To establish a quantitative relationship between the core drilling parameters and the UCS, the monitored drilling parameters $V, N, M$, and $F$ are comprehensively applied to reduce the discreteness of using a single type of drilling parameter. Additionally, to reveal the in-depth rock cutting 


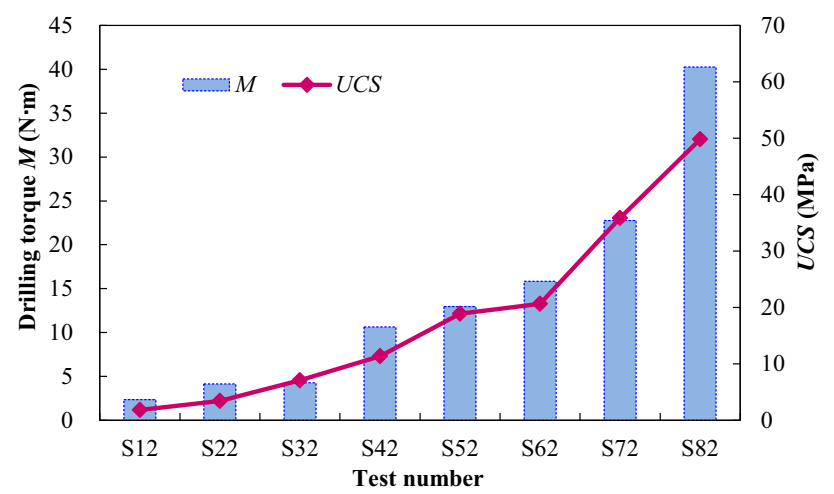

Fig. 6 Analysis of response of drilling torque $M$ to rock UCS

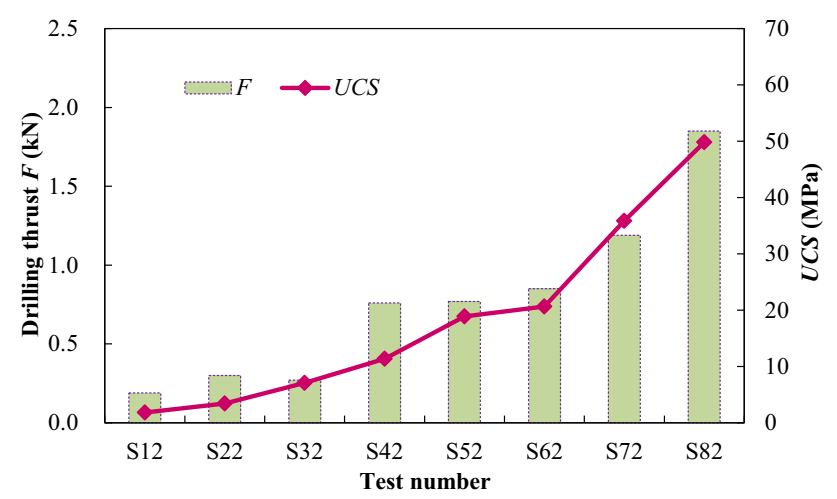

Fig. 7 Analysis of response of drilling thrust $F$ to rock UCS

mechanism of the special digital core bit, a rock cutting mechanical analysis model is created based on the rock cutting failure characteristics, as shown in Fig. 8. As the length of each row of cutting edges greatly exceeds the rock cutting depth over one rotation by a single row of cutting edges (i.e., instantaneous cutting depth $H$ ), the cutting edge is treated as linear motion over each rock cutting cycle, and the rock cutting problem is simplified to a planar strain problem.

The rock cutting mechanical model in Fig. 8 is used to calculate the required torque $M$ for the drill bit to cut rock. This torque contains the cutting torque $M_{c}$ as generated by the horizontal component force of the resistance $F_{c}$ from the front rock on the cutting edge and the friction torque $M_{f}$ generated by the horizontal component of the force $F_{f}$ from the rock at the bottom of the hole on the cutting edges.

As shown in Fig. 9, the radius of the special digital core drilling bit in the test is $R=37.5 \mathrm{~mm}$. The bit contains $n=5$ rows of cutting edges, and the length of each row of the cutting edges is $l=9 \mathrm{~mm}$. The torque generated by the force on an arbitrary microsegment $\mathrm{d} r$ of the cutting edge is:

$\mathrm{d} M=\mathrm{d} M_{c}+\mathrm{d} M_{f}=F_{c} r \cos (\theta+\alpha) \mathrm{d} r+F_{f} r \sin \beta \mathrm{d} r$

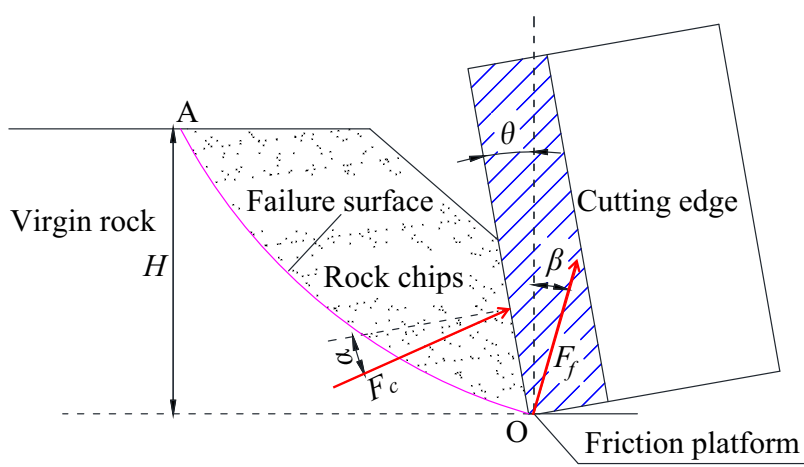

Fig. 8 Rock cutting mechanical analysis model for digital core drilling

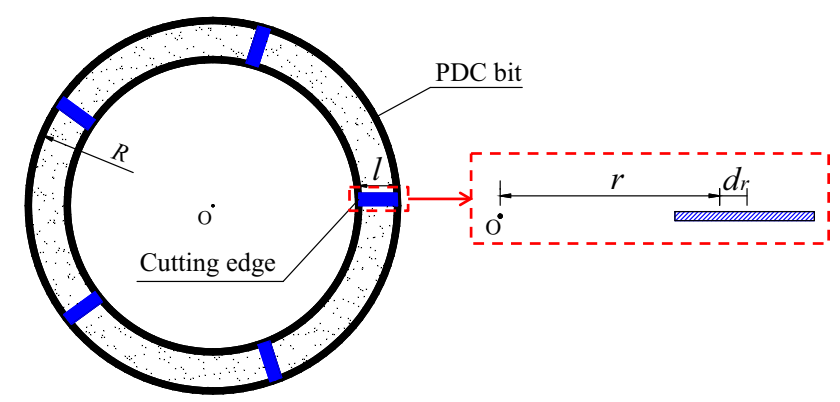

Fig. 9 Special digital core bit and a row of cutting edges

where, $\alpha$ is the angle between the force $F_{c}$ and the normal direction of the cutting edge surface, $\theta$ is the inclination angle of the cutting edge in the special digital core drilling bit $\left(\theta=15^{\circ}\right)$, and $\beta$ is the angle between the force $F_{f}$ and the vertical direction, which is also the friction angle between the cutting edge and the rock. Based on the research results of Huang et al. (2013) and Yahiaoui et al. (2016), $\alpha$ and $\beta$ are set to $12^{\circ}$.

The moments for all the cutting edges of the special digital core bit are superimposed to obtain the drilling torque $M$ as:

$$
\begin{aligned}
M & \left.=n \int_{R-l}^{R}\left[F_{c} \cos (\theta+\alpha)+F_{f} \sin \beta\right)\right] r \mathrm{~d} r \\
& =n l\left(R-\frac{l}{2}\right)\left[F_{c} \cos (\theta+\alpha)+F_{f} \sin \beta\right]
\end{aligned}
$$

The drilling thrust $F$ is equal to the sum of the vertical components of the forces $F_{c}$ and $F_{f}$, as shown in Fig. 8. As shown in Fig. 9, the vertical force $d F$ on an arbitrary microsegment $d r$ of the cutting edges is:

$\mathrm{d} F=\mathrm{d} N_{c}+\mathrm{d} N_{f}=F_{c} \sin (\theta+\alpha) \mathrm{d} r+F_{f} \cos \beta \mathrm{d} r$

The vertical forces for all rows of cutting edges in the special digital core bit are superimposed to obtain the drilling thrust $F$ as: 
Table 4 Statistics of the average DCS and average UCS results for test specimens

\begin{tabular}{|c|c|c|c|c|c|c|c|c|c|}
\hline \multicolumn{2}{|c|}{$\begin{array}{l}\text { No. of } \\
\text { specimens }\end{array}$} & \multirow{2}{*}{$\begin{array}{l}D C S(\mathrm{MPa}) \\
5.52\end{array}$} & \multirow{2}{*}{$\begin{array}{l}\text { Average DCS (MPa) } \\
6.99\end{array}$} & \multirow{2}{*}{$\begin{array}{l}\text { Average } U C S(\mathrm{MPa}) \\
1.81\end{array}$} & \multicolumn{2}{|c|}{$\begin{array}{l}\text { No. of } \\
\text { specimens }\end{array}$} & \multirow{2}{*}{$\begin{array}{l}D C S(\mathrm{MPa}) \\
12.55\end{array}$} & \multirow{2}{*}{$\begin{array}{l}\text { Average DCS (MPa) } \\
12.96\end{array}$} & \multirow{2}{*}{$\begin{array}{l}\text { Average } U C S(\mathrm{MPa} \\
3.02\end{array}$} \\
\hline S1 & S11 & & & & $\mathrm{S} 2$ & $\mathrm{~S} 21$ & & & \\
\hline & $\mathrm{S} 12$ & 7.13 & & & & $\mathrm{~S} 22$ & 14.45 & & \\
\hline & S13 & 8.32 & & & & S23 & 11.87 & & \\
\hline \multirow[t]{3}{*}{$\mathrm{S} 3$} & S31 & 14.00 & 13.44 & 7.17 & $\mathrm{~S} 4$ & S41 & 39.52 & 39.29 & 11.68 \\
\hline & S32 & 16.98 & & & & S42 & 37.57 & & \\
\hline & S33 & 9.33 & & & & S43 & 40.77 & & \\
\hline \multirow[t]{3}{*}{ S5 } & S51 & 49.85 & 54.25 & 19.07 & S6 & S61 & 62.77 & 68.31 & 20.82 \\
\hline & S52 & 53.39 & & & & S62 & 69.72 & & \\
\hline & S53 & 59.50 & & & & S63 & 72.43 & & \\
\hline \multirow[t]{3}{*}{ S7 } & S71 & 107.68 & 110.23 & 35.71 & S8 & S81 & 181.13 & 193.88 & 51.28 \\
\hline & S72 & 103.15 & & & & S82 & 189.20 & & \\
\hline & S73 & 119.84 & & & & S83 & 211.31 & & \\
\hline
\end{tabular}

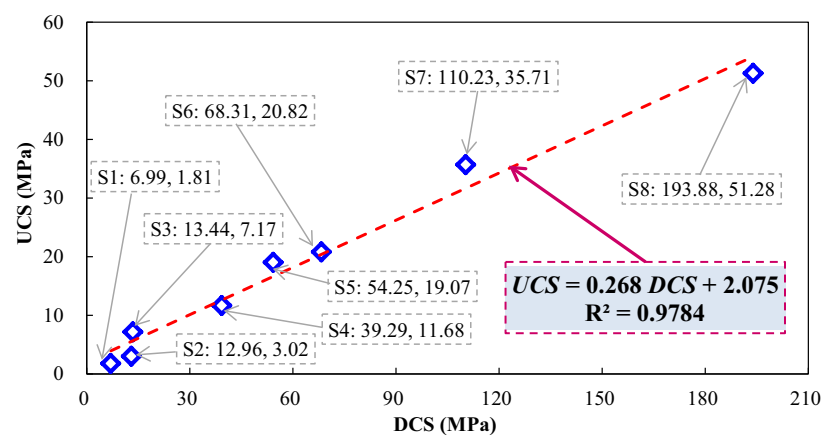

Fig. 10 Scatter diagram of relational analysis for rock DCS and UCS

$$
\begin{aligned}
F & =n \int_{R-l}^{R}\left[F_{c} \sin (\theta+\alpha)+F_{f} \cos \beta\right] \mathrm{d} r \\
& =n l\left[F_{c} \sin (\theta+\alpha)+F_{f} \cos \beta\right]
\end{aligned}
$$

Equations (3) and (5) are combined to eliminate the unknown force $F_{f}$ :

$$
\begin{aligned}
M= & n l(R \\
& \left.-\frac{l}{2}\right)\left[F_{c} \cos (\theta+\alpha)-F_{c} \sin (\theta+\alpha) \tan \beta+\frac{F \tan \beta}{n l}\right]
\end{aligned}
$$

Then, the cutting force $F_{c}{ }^{\prime}$ from the cutting edge on the front rock is:

$$
F_{c}^{\prime}=F_{c}=\frac{2 M-F(2 R-l) \tan \beta}{n l(2 R-l)[\cos (\theta+\alpha)-\sin (\theta+\alpha) \tan \beta]}
$$

The digital core drilling strength (DCS), whose physical significance is the cutting force of the special digital core drilling bit when cutting a unit area of rock, is obtained as:
$D C S=\frac{F_{c}^{\prime}}{S}=\frac{N[2 M-F(2 R-l) \tan \beta]}{V l(2 R-l)[\cos (\theta+\alpha)-\sin (\theta+\alpha) \tan \beta]}$

where, the rock cutting area corresponding to the cutting force $F_{c}^{\prime}$ is $S=H \times 1$ under the assumption of a planar strain problem. The instantaneous cutting depth of rock is $H=V / n N$. Based on the rock cutting mechanical analysis, the obtained drilling parameters $V, N, M$, and $F$ for each specimen are substituted into Eq. (8) to obtain the rock DCS. The average values of the DCS and UCS in the three plans for the mortar specimen and the sandstone specimen of the same grade are the average DCS and the average UCS for this grade. The detailed results are given in Table 4.

\subsection{Established relational model for drilling parameters and rock UCS}

A scatter plot from the relationship analysis of the rock DCS and UCS is shown in Fig. 10 based on the average values of the DCS and UCS for the test specimens in Table 4.

The analysis of Fig. 10 indicates that the rock DCS obtained from the core drilling tests increases with the rock UCS, and the two have a high degree of linear response correlation. Based on the digital core drilling test results for the sandstone and cement mortar specimens with a strength range of $1.56-55.68 \mathrm{MPa}$, the quantitative relationship formula for the rock DCS and UCS is obtained via linear regression, as shown in Eq. (9). The linear goodness of fit $R^{2}$ is 0.9784 , which indicates that the rock DCS and UCS have a high degree of fit.

$U C S=0.268 D C S+2.075$ 
Based on this established linear quantitative relational formula for the rock DCS and rock UCS, Eq. (8) is substituted into (9) to obtain a quantitative relationship model (CDP-UCS model) for the digital core drilling parameters and UCS, as shown in Eq. (10).

$$
U C S=0.268 \frac{N[2 M-F(2 R-l) \tan \beta]}{V l(2 R-l)[\cos (\theta+\alpha)-\sin (\theta+\alpha) \tan \beta]}+2.075
$$

\subsection{Establishment of real-time in situ forecast method for rock UCS}

The research results for the relationship between the drilling parameters and the rock UCS provide a promising concept for rock UCS forecasting. Based on the established CDP-UCS model, a digital core drilling parameter-based rock UCS forecast method is proposed. Its procedure is given as follows:

(1) The surrounding rock digital core drilling test is performed based on a digital drilling test system for underground engineering. The drilling parameters $V$, $N, M$, and $F$ over the entire drilling range are obtained.

(2) The surrounding rock UCS distribution law over the entire drilling range is obtained based on the CDPUCS model in Eq. (10).

During the application of the rock UCS forecast method, the UCS values of the rock core samples obtained from laboratory tests are compared with the forecasted values from the CDP-UCS model for verification. The CDP-UCS model is continuously modified to ensure accurate forecasts. The continuous and real-time acquisition of the surrounding rock UCS during construction can guide the design and prompt optimization of support plans based on the geological conditions to ensure construction safety.

\section{Conclusions}

(1) The digital core drilling test and the uniaxial compression test are conducted on 24 groups of cement mortar specimens and sandstone specimens with various strength grades to determine the drilling parameters $V, N, M$, and $F$, which are monitored during drilling, as well as the rock UCS based on the rock mass digital drilling system and the special digital core drilling bit developed by the authors.

(2) The response laws of the drilling torque $M$ and the drilling thrust $F$ to the rock UCS are analyzed. The results indicate that the variation laws for $M$ and $F$ to the rock UCS are consistent, and both demonstrate an overall increasing trend for a larger rock UCS. Thus, $M$ and $F$ are highly responsive to the rock UCS.

(3) Based on the rock cutting fracture characteristics of the core drilling, the mechanical analysis of rock cutting is performed to obtain the calculation model for the digital core drilling strength. The average rock DCS of the cement mortar specimens and sandstone specimens for various grades is obtained based on the drilling parameters measured in the digital core drilling tests.

(4) A quantitative relationship model (CDP-UCS model) for the digital core drilling parameters and rock UCS is established based on the digital core drilling testing results for sandstone and cement mortar specimens with a strength range of 1.56-55.68 MPa. Thus, a digital core drilling-based rock UCS forecast method is proposed. Digital core drilling tests for intact rock with a wide strength range and weak fractured rock mass will be performed to propose a rock UCS forecast method with a wide application range. This method provides a technical solution for continuous and quick acquisitions of the surrounding rock UCS.

Authors' contributions HG: He designs the digital core drilling tests plan and writes the paper. QW: He guides the ideas of the paper and assists in writing the article. BJ: She conducts the mechanical analysis of rock cutting. PZ: He conducts the digital core drilling tests and analyzes the test data. $\mathrm{ZJ}$ : He assists in conducting the digital core drilling tests. YW: He assists in analyzing the test data.

Funding This work was supported by the Natural Science Foundation of China (Nos. 51874188, 51927807, 41941018 and 51704125); the State Key Laboratory for GeoMechanics and Deep Underground Engineering, China University of Mining \& Technology (No. SKLGDUEK1717); the Major Scientific and Technological Innovation Project of Shandong Province, China (No. 2019SDZY04); the Project of Shandong Province Higher Educational Youth Innovation Science and Technology Program (No. 2019KJG013).

Data availability The data supporting the findings can be found in the figures, tables and manuscript.

\section{Compliance with ethical standards}

Conflict of interest The authors declare that they have no conflict of interest.

Open Access This article is licensed under a Creative Commons Attribution 4.0 International License, which permits use, sharing, adaptation, distribution and reproduction in any medium or format, as long as you give appropriate credit to the original author(s) and the source, provide a link to the Creative Commons licence, and indicate if changes were made. The images or other third party material in this article are included in the article's Creative Commons licence, unless indicated otherwise in a credit line to the material. If material is not 
included in the article's Creative Commons licence and your intended use is not permitted by statutory regulation or exceeds the permitted use, you will need to obtain permission directly from the copyright holder. To view a copy of this licence, visit http://creativecommons. org/licenses/by/4.0/.

\section{References}

Aalizad SA, Rashidinejad F (2012) Prediction of penetration rate of rotary-percussive drilling using artificial neural networks-a case study. Arch Min Sci 57(3):715-728

Ataei M, Kakaie R, Ghavidel M, Saeidi O (2015) Drilling rate prediction of an open pit mine using the rock mass drillability index. Int J Rock Mech Min Sci 73:130-138

Cao RH, Cao P, Lin H (2016) Support technology of deep roadway under high stress and its application. Int J Min Sci Technol 26(5):787-793

Chen ML, Jing HW, Ma XJ, Su HJ, Du MR, Zhu TT (2017) Fracture evolution characteristics of sandstone containing double fissures and a single circular hole under uniaxial compression. Int $\mathrm{J}$ Min Sci Technol 27(3):499-505

Dehghan S, Sattari G, Chelgani SC, Aliabadi M (2010) Prediction of uniaxial compressive strength and modulus of elasticity for Travertine samples using regression and artificial neural networks. Min Sci Tech 20(1):41-46

Ersoy A (2003) Automatic drilling energy using PDC control based on minimum drilling specific and WC bits. Min Tech 112(2):86-96

Fattahi H, Bazdar H (2017) Applying improved artificial neural network models to evaluate drilling rate index. Tunn Undergr Sp Tech 70:114-124

Goktan RM, Gunes N (2005) A comparative study of Schmidt hammer testing procedures with reference to rock cutting machine performance prediction. Int J Rock Mech Min Sci 42:466-472

Gui MW, Soga K, Bolton MD, Hamelin JP (2002) Instrumented borehole drilling for subsurface investigation. J Geotech Geoenviron Eng 128(4):283-291

Heidari M, Khanlari GR, Kaveh MT, Kargarian S (2012) Predicting the uniaxial compressive and tensile strengths of gypsum rock by point load testing. Rock Mech Rock Eng 45(2):265-273

Huang H, Lecampion B, Detournay E (2013) Discrete element modeling of tool-rock interaction I: rock cutting. Int J Numer Anal Meth Geomech 37(13):1913-1929

Kaya A, Karaman K (2016) Utilizing the strength conversion factor in the estimation of uniaxial compressive strength from the point load index. Bull Eng Geol Environ 75(1):341-357

Kumar BR, Vardhan H, Govindaraj M (2011) Prediction of uniaxial compressive strength, tensile strength and porosity of sedimentary rocks using sound level produced during rotary drilling. Rock Mech Rock Eng 44(5):613-620

Li ZT, Itakura K (2012) An analytical drilling model of drag bits for evaluation of rock strength. Soils Found 52(2):216-227

Liu Y, Dai F, Dong L, Xu NW, Feng P (2018) Experimental investigation on the fatigue mechanical properties of intermittently jointed rock models under cyclic uniaxial compression with different loading parameters. Rock Mech Rock Eng 51(1):47-68

Meng QB, Zhang MW, Han LJ, Pu H, Nie TY (2016) Effects of acoustic emission and energy evolution of rock specimens under the uniaxial cyclic loading and unloading compression. Rock Mech Rock Eng 49(10):3873-3886

Moradian ZA, Behnia M (2009) Predicting the uniaxial compressive strength and static Young's modulus of intact sedimentary rocks using the ultrasonic test. Int J Geomech 9(1):14-19
Munoz H, Taheri A, Chanda EK (2016) Rock drilling performance evaluation by an energy dissipation based rock brittleness index. Rock Mech Rock Eng 49(8):3343-3355

Ozturk H, Altinpinar M (2017) The estimation of uniaxial compressive strength conversion factor of trona and interbeds from point load tests and numerical modeling. J Afr Earth Sci 131:71-79

Sharma LK, Vishal V, Singh TN (2017) Developing novel models using neural networks and fuzzy systems for the prediction of strength of rocks from key geomechanical properties. Measurement 102:158-169

Sugawara J, Yue ZQ, Tham LG, Law KT, Lee CF (2003) Weathered rock characterization using drilling parameters. Can Geotech J 40(3):661-668

Tiryaki B (2008) Predicting intact rock strength for mechanical excavation using multivariate statistics, artificial neural networks, and regression trees. Eng Geol 99(1-2):51-60

Torabi-Kaveh M, Naseri F, Saneie S, Sarshari B (2015) Application of artificial neural networks and multivariate statistics to predict UCS and E using physical properties of Asmari limestones. Arab J Geosci 8(5):2889-2897

Wang H, Lin H, Cao P (2017) Correlation of UCS rating with schmidt hammer surface hardness for rock mass classification. Rock Mech Rock Eng 50:195-203

Wang Q, Pan R, Jiang B, Li SC, He MC, Sun HB, Wang L, Qin Q, Yu HC, Luan YC (2017) Study on failure mechanism of roadway with soft rock in deep coal mine and confined concrete support system. Eng Fail Anal 81:155-177

Wang Q, He MC, Yang J, Gao HK, Jiang B, Yu HC (2018) Study of a no-pillar mining technique with automatically formed gob-side entry retaining for longwall mining in coal mines. Int $\mathbf{J}$ Rock Mech Min Sci 110:1-8

Wang Q, Qin Q, Jiang B, Yu HC, Pan R, Li SC (2019) Study and engineering application on the bolt-grouting reinforcement effect in underground engineering with fractured surrounding rock. Tunn Undergr Sp Tech 84:237-247

Wang Q, Jiang ZH, Jiang B, Gao HK, Huang YB, Zhang P (2020) Research on an automatic roadway formation method in deep mining areas by roof cutting with high-strength bolt-grouting. Int J Rock Mech Min Sci 128:104264

Wang Q, Xin ZX, Jiang B, Sun HB, Xiao YC, Bian WH, Li LN (2020) Comparative experimental study on mechanical mechanism of combined arches in large section tunnels. Tunn Undergr Sp Tech 99:103386

$\mathrm{Xu} \mathrm{Y,} \mathrm{Dai} \mathrm{F} \mathrm{(2017)} \mathrm{Dynamic} \mathrm{response} \mathrm{and} \mathrm{failure} \mathrm{mechanism} \mathrm{of}$ brittle rocks under combined compression-shear loading experiments. Rock Mech Rock Eng 51(3):747-764

Yahiaoui M, Paris JY, Delbé K, Denape J, Gerbaud L, Dourfaye A (2016) Independent analyses of cutting and friction forces applied on a single polycrystalline diamond compact cutter. Int J Rock Mech Min Sci 85:20-26

Yang RS, Li YL, Guo DM, Yao L, Yang TM, Li TT (2017) Failure mechanism and control technology of water-immersed roadway in high-stress and soft rock in a deep mine. Int J Min Sci Technol 27(2):245-252

Yaşar E, Ranjith PG, Viete DR (2011) An experimental investigation into the drilling and physico-mechanical properties of a rock-like brittle material. J Petrol Sci Eng 76(3-4):185-193

Yesiloglu-Gultekin N, Gokceoglu C, Sezer EA (2013) Prediction of uniaxial compressive strength of granitic rocks by various nonlinear tools and comparison of their performances. Int J Rock Mech Min Sci 62:113-122

Yue ZQ, Lee CF, Law KT, Tham LG (2004) Automatic monitoring of rotary-percussive drilling for ground characterization-illustrated by a case example in Hong Kong. Int J Rock Mech Min Sci 41(4):573-612 